compared with fructose, and this is likely to be caused by the accelerated transport of hexoses through the nuclear membrane ${ }^{3}$. ATP is involved in the hexokinase reaction and more ADP is obtained which, as an acceptor of the freshly synthesized high energy phosphates, has an activating effect on oxidative phosphorylation in the nuclei. Activation of the oxidative phosphorylation can account for the increase, under the effect of insulin, of both the phosphate ester and ATP. On the other hand, the changes in the ATP content under the effect of insulin may be caused by its control of certain enzymes of glyconeogenesis ${ }^{11}$ and also by control of the biological oxidation and its coupling with oxidative phosphoryla. tion $^{12}$. In support of the latter assumption are the activating effects of adenosine and of insulin on the oxygen consumption by the nuclei which are not additive when the nuclei are incubated in the presence of insulin and adenosine? $\theta^{7}$ The increased RNA content in some samples is too high to be explained merely as a synthesis of RNA, as was shown for liver cells ${ }^{10}$. In view of the fact that the calf thymus nuclei contain natural polyadenylic acid ${ }^{8}$, it is possible that the increased amount of RNA results to a certain extent from the synthesis of polyadenylic acid. The results of the investigations of Allfrey et $a l .^{1}$ on the influence of insulin on the transport of amino-acids cannot be accepted as absolutely reliable because we have established that the insulin affects the carbohydrate metabolism in them as well. Because in our experiments the nuclei were incubated in a medium containing glucose as well, it is possible for the accelerated protein synthesis to be the result of a larger supply of ATP to the nuclei rather than a direct effect of the insulin on the transport of the amino-acids.

Department of Biochemistry,

K. I. Dancheva

High Medical Institute,

G. Sofiiski str. 1,

Sofia 32, Bulgaria.

'Allfrey, V. G., Mentt, R., Hopkins, J. W., and Mirsky, A. E., Proc. U.S. Nat. Acad. Sci., 47, 907 (1961).

'Betel, J., and Klowen, H. M., Second Meeting of the European Biochem. Soc. Abstracts, 111 (Fed. Osterreich. Biochem. Gesellschaft, Vienna, 1965). Bukureshtliev, A. D., in Functional Biochemistry (edit. by Hadjiolov, A. A.),
487 (Medizina and Physkultura, Softa, 1964).

- Crabtree, H. G., Biochem. J., 23, 536 (1929).

${ }^{5}$ Dancheva, K. I., C.R. de l'Academie Bulgare des Sciences, 18, No. 5, 469 (1965).

- Dancheva, K. I., Biochemija, 30, 1037 (1965).

'Dancheva, K. I. (in the press).

${ }^{8}$ Edmonds, H. R., and Abrams, R., J. Biol. Chem., 237, 2637 (1962).

-McEwen, Br. S., Allfrey, V. G., and Mirsky, A. E., J. Biol. Chem., 238, 758,2579 (1963).

${ }^{10}$ Glock, G. E., and McLeon, P., Biochim. Biophys. Acta, 16, 446 (1955).

${ }^{11}$ Krebs, H., Plenary Lecture of the Second Meeting of the European Biochem. Krebs, H., Plenary Lecture of the Second Meeting of the European Biochen.
Soc. Abstracts (F'ed. Osterreich. Biochem. Gesellschaft, Vienna, 1965).

${ }^{12}$ Liljeroot, B. S., and Hall, J. C., J. Biol. Chem., 240, 1446 (1965).

ts Schneider, W. C., Methods in Enzymology (edit. by Colowicks and Kaplan), 3, 681 (Academic Press, N.Y., 1957).

\section{Transferrin Variants in Carp Serum}

A TRANSFERRIN polymorphism in carp serum was reported earlier ${ }^{1}$ which was very similar to that demonstrated in sera from a number of animal species ${ }^{2-8}$. It is easy to detect transferrin components by means of starch gel electrophoresis, because they are usually present in large quantities and because they have distinctive properties. Radioactive labelling (iron-59) makes possible a more accurate identification of the protein. We isolated carp transferrins by zone electrophoresis and gel filtration ${ }^{9}$. There is evidence that the heterogeneity displayed by starch gel by some transferrins is related to electrokinetic properties of the distinct transferrin components, but no such lack of homogeneity has been proved to exist ${ }^{9}$.

Sera were obtained from fish bred in ponds near Lyon (France) (étangs des Dombes) as previously described ${ }^{1}$. One hundred and fourteen serum samples from different individuals were investigated. The actual number and

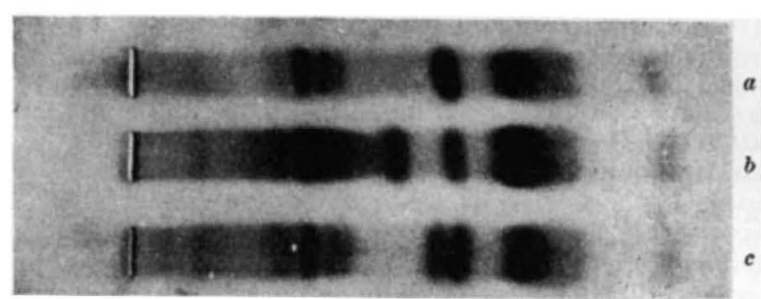
Fig. 1. Electrophoretic pattern of carp serum on starch gel. $a$, Pheno-
type $T f A ; b$, phenotype $T f A C ; c$, phenotype $T f A B$.

location of the transferrin components were determined by starch gel electrophoresis, according to the method devised by Poulik ${ }^{10}$, with a discontinuous buffer system. This buffer system makes the identification of the transferrin variants easier than Smithies's buffer. It is possible. therefore, in most cases to avoid the check with iron-59.

Experimental data were compared with data calculated from the hypothesis of a genetically controlled variation.

One or two transferrin components have been found in individual samples of carp serum (Fig. 1). Three transferrin variants were defined by electrophoretic displacement in starch gel. We have termed these, in order of anodic mobility, Tf $A, T f B$ and $T f C$. This suggests that there are six different phenotypes. A genetically controlled polymorphism is supposed to exist; that is, the polymorphic character of carp transferrin ought to be determined by a gene (non-dominant) with three alleles.

In the present work (114 individuals) the frequency of the three alleles is: $A, 0.58333 ; B, 0.24123 ; C, 0.17544$.

According to the hypothesis of a random association of two alleles from the three so far demonstrated, it is possible to compute the theoretical frequency of the six phenotypes. These are compared statistically with experimental data in Table 1.

Table 1. Experimental and Theoretical Frequencies of Phenotypes

$\begin{array}{lcccc} & \text { Frequency (experimental) } & \text { Frequency } & \text { (computed) } \\ \text { Phenotype } & \text { No. } & \text { Per cent } & \text { No. } & \text { Per cent } \\ \text { Tf } A & 40 & 35 \cdot 09 & 38 \cdot 8 & 34 \cdot 03 \\ \text { Tf } B & 7 & 6 \cdot 14 & 6 \cdot 6 & 5 \cdot 82 \\ \text { Tf } C & 4 & 3 \cdot 51 & 3 \cdot 5 & 3 \cdot 08 \\ \text { Tf } A B & 31 & 27 \cdot 19 & 32 \cdot 1 & 28 \cdot 14 \\ \text { Tf } B C & 10 & 8 \cdot 77 & 9 \cdot 6 & 8 \cdot 46 \\ \text { Tf } A C & 22 & 19 \cdot 30 & \underline{23 \cdot 3} & 20 \cdot 47 \\ & 114 & 100 \cdot 00 & \underline{113.9} & 100 \cdot 00\end{array}$

Good agreement exists between the observed and computed values: $\chi^{2}=0 \cdot 244$; degrees of freedom, $2 ; P=$ 0.98 .

These results thus provide support for the hypothesis of a genetic polymorphism controlled by three existing alleles; however, a thorough investigation involving the examination of several generations of animals is necessary before the existence of a hereditary variation in carp transferrin synthesis can be established.

R. Creyssel G. B. RICHARD

Institut Pasteur,

Lyon.

\section{P. Silberzahn}

Laboratoire de Physiologie,

Faculté des Sciences,

Lyon.

${ }^{2}$ Creyssel, R., Silberzahn, P., Richard, G., and Manuel, Y., Bull. Soc. Chim. Biol., 46, 148 (1964)

2 Beckmann, L., Hirschfeld, J., and Soderberg, U., Acta Path. Microbiol. Scand., 51, 132 (1961).

${ }^{3}$ Blumberg, B. S., Proc. Soc. Exp. Biol. Med., 104, 25 (1960).

Broend, M., Nature, 203, 674 (1964).

${ }^{5}$ Buschmann, H., and Schmid, D. O., Nature, 190, 1209 (1961).

' Fine, J. M., Drilhon, P., Boffa, G. A., and Amouch, P., Protides of Biological Fluids, Proc. of Twelfth Colloquium of Bruges, 165 (Elsevier, 1965).
(E) .

' Ogden, A. L., Morton, J. R., Gilmour, D. G., and McDermid, E. M., Nature, 195,1026 (1962).

${ }^{\text {s }}$ Scopes, R. K., Nature, 197, 1201 (1963).

- Richard, G. B., Silberzahn, P., and Creyssel, R., Bull. Soc. Chim. Biol. (in the press).

10 Poulik, M. D., Nature, 180, 1477 (1957). 